The theoretical $B^{*}$ is marked by an asterisk to distinguish it from the observed $B$, which is defined by the conventional formula

$$
\Delta L=x_{0}+y_{0} T+z_{0} T^{2}+B,
$$

in which $x_{0}, y_{0}$ and $z_{0}$ are fixed values derived from the papers of De Sitter and adopted by Spencer Jones, Clemence and Brouwer.

From Eqs. (6), (7) and (8) we obtain, eliminating $\Delta L$,

$$
B^{*}=B-\left(a+b T+c T^{2}\right)=k \int_{0}^{T} \theta d T .
$$

The problem is to find out whether the constants $a, b$ and $c$ can be determined in such a way that

$$
B^{*}=B-\left(a+b T+c T^{2}\right)
$$

behaves like an integral $k \int_{0}^{T} \theta d t$, as it should do according to the theory, to estimate the constants

$$
a=x-x_{0}, \quad b=y-y_{0}, \quad c=z-z_{0}
$$

and to estimate the standard errors of the estimates of $b$ and $c$.

Putting $t=0$ in Eq. (9), we obtain $a=B(0)$. This means that in 1900 mean Greenwich coincided with actual Greenwich. This is an arbitrary convention, which may be changed at will.

Subtracting (9) for $T+\frac{1}{2} \delta T$ and $T-\frac{1}{2} \delta T$, and dividing by $\delta T$, we obtain

$$
k \bar{\theta}=\frac{\delta B}{\delta T}-(b+2 c T) .
$$

Here $\bar{\theta}$ is the integral mean of $\theta$ over the period $\delta T$, of which $T$ is the middle; $\delta B$ is the observed change of $B$ during this period. The expectation of $\bar{\theta}$ is zero, hence:

$\mathrm{b}+2 \mathrm{cT}$ is the expectation of the observed difference quotient $\delta \mathrm{B} / \delta \mathrm{T}$ over any period $\delta \mathrm{T}$.

A statistical analysis of the observed $\delta B$ 's by Van Woerkom shows that differences $\delta B$, taken for two one-year periods less than Io or 12 years apart, have a high positive correlation, but if the periods are taken 20 or more years apart, the correlation practically vanishes. This is just what was to be expected from theory. The analysis was based upon I30 differences $\delta B$ of $B$-values observed in successive years.

An estimation of $b$ and $c$ from ancient, medieval and modern observations by a modified method of least squares based upon the statistical properties of the $\delta B$ 's, resulted in $z=z_{0}+c=6$.I.

This estimate has a standard error of approximately 0.8 . The deviations of the observed $B$ 's from the parabola $B=a+b T+c T^{2}$ were not larger than might be expected from the variance of the $\delta B$ 's and the errors of the ancient observations.

\title{
FLUCTUATIONS AND SECULAR CHANGES IN THE EARTH'S ROTATION
}

\author{
By DIRK BROUWER \\ Yale University Observatory, New Haven, Connecticut
}

\begin{abstract}
Geophysical considerations favor seeking the cause of the random changes in the earth's rate of rotation in the turbulent motion in the core of the earth. Professor van der Waerden's analysis applies to this interpretation. The observational evidence indicates that the character of the fluctuation curve may be intermediate between that expected on the basis of a theory with frictional couple and one without. If confirmed, this would indicate that two different causes contribute to the changes in the earth's rate of rotation.
\end{abstract}

Seven years ago (Brouwer I952a,b) I attempted a solution of the problem of the irregular changes in the earth's rate of rotation by assuming that the second differences of the annual values of the fluctuation curve in the moon's mean longitude are of a random character, uncorrelated from one year to the next. These second differences were assumed to have a normal distribution with a fixed standard deviation to be determined from the observational data. Their mean value would differ from zero by a small quantity corresponding to a correction to the secular acceleration term in the moon's tabular mean longitude.
The analysis was tested by Van Woerkom (I953) in two ways: by examining the properties of artificially constructed fluctuation curves and by a statistical discussion of the annual values of the observed fluctuation curve since 1820 . He concluded that, on the whole, the observational data support the hypothesis, but that there may be an unexplained contribution to the variance of the first differences. Also, the amplitude of the observed fluctuations over the twenty centuries for which scattered data are available appears to be rather smaller than might be expected from the character of the fluctuations since 1820. Comparison with arti- 
ficially constructed fluctuation curves shows that this situation is improbable but not impossible. For the standard deviation of the random annual second differences Van Woerkom found values between $0^{8} \mathrm{I} 4$ and $0^{8} .22$ in time, corresponding to $0 . .08$ to 0 ". 12 in seconds of arc in the moon's mean longitude. The uncertainty is primarily due to the observational errors that affect the annual values.

To some extent these discussions were independent of a formulation of the physical causes of the phenomenon. It may be said, however, that the assumption of mass movements in the earth's interior, affecting the moment of inertia about the axis of rotation, is in agreement with the hypothesis.

Munk and Revelle (1952) presented a comprehensive discussion of the geophysical problems that concern us here, and gave strong arguments in favor of seeking the cause of the random changes in the turbulent motion in the core of the earth. Important indirect reasons in favor of this explanation are:

(I) The variations in the westward drift of the magnetic field of the earth between 1890 and I950 show the proper relationship, qualitatively and quantitatively, to the observed changes in the length of the day.

(2) The small displacements of the pole of rotation are consistent only with nearly symmetrical disturbances, which are difficult to bring into agreement with the mass-movement hypothesis.

Dr. van der Waerden's discussion applies to the explanation proposed by Munk and Revelle. The new element that he introduces is a frictional couple proportional to $\Omega-\omega$, the difference between the angular velocity of the earth as a whole and the variable angular velocity of the mantle.

The presence of the frictional couple affects the character of the fluctuation curve in an important way. The first differences of the fluctuation curve, instead of being the sum of random contributions with mean value zero superposed on a linear function of the time, now must be satisfied by

$$
\Delta B=\alpha+\beta T+\int_{0}^{\infty} \epsilon(T-t) e^{-g t} d t
$$

in which $\epsilon(T)$ is a random variable with expectation zero. Assume for the purpose of discussion that the values of $\epsilon(T)$ are uncorrelated from one year to the next. Then the integral may be replaced by

$$
\epsilon_{0}+\epsilon_{-1} e^{-g}+\epsilon_{-2} e^{-2 g}+\cdots \cdot
$$

Except for corrections at the beginning and the end of the interval that become insignificant for large values of $n$, the sum for $n$ years is

$$
\left(\sum_{1}^{n} \epsilon_{j}\right) /\left(\mathbf{I}-e^{-\theta}\right) .
$$

The expectation of this sum is zero, but the deviations from zero have the mean value $\sigma \sqrt{n}$, if $\sigma$ is the r.m.s. value of $\epsilon_{j}$. This compares with an accumulation of the order $\sigma n^{\frac{1}{2}}$ for the solution without frictional term. Without frictional term the evaluation of the secular acceleration in the moon's mean longitude is affected by a large uncertainty due to the random process. This near-indeterminateness disappears with the introduction of the frictional term.

The residuals obtained by Van der Waerden's solution are larger than would be compatible with this assumption. For the moment we can conclude only that with his theory the assumption of independent values of $\epsilon$ from year to year fails to satisfy the observed fluctuation curve.

However, Van der Waerden's theory does not require that the values of $\epsilon$ are independent from year to year; he postulates only that $\epsilon\left(T_{1}\right)$ and $\epsilon\left(T_{2}\right)$ at times $T_{1}$ and $T_{2}$ far apart are practically independent and that the mean value of $\epsilon$ over a long interval of time, which may be several centuries, is zero.

Pending further study of the problem, it would appear as if the observed fluctuation is intermediate between the two interpretations: one with frictional couple, and one without frictional couple. A not very attractive hypothesis is that the observed phenomenon is the result of two processes acting simultaneously. Munk and Revelle remark at the end of their paper that organized crustal movement, even if a priori unlikely, cannot be altogether ruled out as a possible cause for the fluctuations in the length of the day.

A more detailed statistical analysis of the fluctuation curve is clearly needed. As I remarked earlier, the observational errors in the annual values of $B$ since 1820 complicate the precise evaluation of the random contributions. The more accurate values that can now be obtained and on which Dr. Markowitz is reporting should be of great aid in clarifying the issue. 
Finally, the values of the secular variations in the mean longitudes of the sun and the moon depend on scanty available data before the early seventeenth century. Any new information on ancient observations will be extremely important.

\section{REFERENCES}

Brouwer, D. 1952a, Proc. Nat. Acad. Sci. 38, I. . I952b, A. J. 57, I25.

Munk, W. and Revelle, R. 1952, M. N. Geophys. Suppl. 6, 331 .

Van Woerkom, A. J. J. 1953, A. J. 58, 10.

\section{VARIATIONS PERIODIQUES ET ALEATOIRES DE LA ROTATION DE LA TERRE}

PAR NICOLAS STOYKO

Bureau International de l'Heure, Observatoire de Paris, Paris, France

Résumé. Etude de la periode 1952-1958 a montré la stabilité assez grande de la variation saisonnière de la rotation de la Terre par rapport à l'heure definitive. Nous avons trouvé

$$
S=0,0240 \sin (j-3 \mathrm{I})+0,0072 \sin 2(j+70),
$$

où $j$ est exprimé en jours moyens à partir du $\mathrm{I}^{\mathrm{er}}$ janvier.

La comparaison avec le temps terrestre des étalons atomiques de fréquence à césium a permis de trouver que la vitesse moyenne de la rotation de la Terre varie d'une façon aléatoire pendant les trois dernières années. Pour la période du juin au novembre 1955 la durée du jour diminue (la Terre accélere) de $2 \times 10^{-5} \mathrm{sec}$. par mois, du decembre 1955 au mai I957 la durée du jour augmente progressivement (la Terre retarde) en moyenne de $4 \times 1^{-5}$ sec. par mois et à partir du mai I957 elle est presque constante.

Ainsi, l'extrapolation du temps rotationnel terrestre par rapport au temps atomiques présente des grandes difficultés

On peut diviser en deux périodes les études des irrégularités de la rotation de la Terre de courte durée:

I. Utilisation des horloges à quartz et des pendules à partir de 1933.

2. Introduction de l'étalon atomique à césium du National Physical Laboratory à Teddington construit par M. L. Essen à partir de juin 1955 .

Quand on utilise les marches des horloges à quartz pour l'étude de l'irrégularité de la rotation de la Terre, on détermine seulement les termes périodiques, dont les périodes ne dépassent pas sensiblement une année. Les variations progressives aléatoires de la rotation de la Terre sont mélangées avec les variations progressives de la marche des horloges.

Après l'introduction de l'étalon atomique à césium qui est comparé régulièrement avec les émissions de Rugby (MSF), il est devenu possible de déterminer les variations périodiques et aléatoires dans la rotation de la Terre.

Nous avons repris le calcul de l'irrégularité saisonnière de la rotation de la Terre à partir de l'année I952. Les résultats jusqu'au mois de mai I 955 sont calculés en utilisant les horloges à quartz et les heures définitives du Bureau International de l'Heure (B.I.H.). Nous avons utilisé les horloges à quartz de Greenwich, Neuchâtel, Paris, Potsdam et Washington.

Les résultats jusqu'en janvier 1958 sont rapportés à l'heure définitive ou à la moyenne de plus de 20 services horaires. Les résultats des mois de février et mars 1958 sont rapportés, respectivement, à la moyenne de ro et 6 services horaires.

Dans le cas d'étude de l'irrégularité saisonnière de la rotation de la Terre en utilisant les horloges à quartz, il faut déterminer les variations progressives de la marche des horloges. Dans le cas d'utilisation de l'étalon atomique, il faut éliminer la variation progressive de sa fréquence par rapport au TU2 (Temps Universel uniforme provisoire). Cette variation provient du changement progressif de la vitesse de la rotation de la Terre. Les premières études des résultats de l'étalon atomique (Stoyko et Stoyko 1958; Essen, Parry, Markowitz et Hall I958) ont montré que la fréquence de l'étalon à césium augmente linéairement de $40 \mathrm{~Hz}$ par an, c'est à dire sa fréquence par rapport à TU2 devrait être au mois de mars I958 égale à 9, 192,631, $945 \mathrm{~Hz}$, étant donné que la fréquence conventionnelle du départ (juin 1955) est égale à 9, I82, 631, $830 \mathrm{~Hz}$.

L'étude plus détaillée de la variation progressive de la fréquence de l'étalon à césium a montré que sa variation n'est pas linéaire. En prenant les différences de fréquence pour l'intervalle de I2 mois, afin d'éliminer la variation saisonnière, on trouve que ces différences augmentent linéairement jusqu'au milieu de l'année 1957, tandis que, après cette date, elles diminuent. Cela nous montre que la vitesse de la rotation de la Terre exprimée en TU2 a des variations aléatoires. Dans le Tableau I, nous donnons les variations de la durée du jour d'après l'étalon à césium 